\title{
Transparency and surveillance of end users on social media platforms
}

\author{
A view of structural economic factors
}

\author{
Abel Reiberg
}

\section{Introduction}

Over the past two decades users of social media platforms have been subject to intensive surveillance by various actors. Surveillance has been used by, for example, end users in cases of digital stalking, private companies providing third-party apps in cases like the Cambridge Analytica scandal, and government agencies, as in the case of the National Security Agency's surveillance programs. These actors, however, were able to engage in surveillance only because platform providers have designed platforms to accumulate vast amounts of personal data. In this sense, it is the providers of the platform who enable surveillance. It is first and foremost they who initiate, oversee, and steer the flows of information on the platform. In order to explain the interaction of transparency and surveillance on social media platforms, therefore, the interests of platform providers need to be studied. This chapter addresses the question of why platform providers have furthered transparency and surveillance of end users by investigating the providers' economic interests.

The structure of this chapter is as follows: the second section of this chapter discusses the relationship between transparency and surveillance. It is argued that transparency allows actors to carry out the monitoring that is an essential part of surveillance and that transparency can therefore be understood as a precondition to surveillance. The third section then addresses the question of why providers of social media platforms have both the ability and the interest in furthering transparency and surveillance of end users on their platforms. Here it is argued that the ability to further the transparency of end users relies on the centralization in markets for social media and that this centralization, in turn, is due to economies of scale, particularly those on the demand side. Furthermore, it is argued that the underlying interest in furthering transparency and surveillance relies on the particular multisided market strategies of the platform providers. In order to illustrate the argument, the strategies applied by Facebook, the provider of the largest social media platform, with regard to end users, developers, and advertising clients are considered. 
A summary of this chapter's results and limitations is provided in the concluding section.

\section{On the relationship between transparency and surveillance}

References to transparency in political discourse usually have a positive connotation; there are, however, telling exceptions. On December 14, 1996, the German newspaper Süddeutsche Zeitung" published a commentary titled "the transparent citizen." With surprising foresight, the data protection officer of the state of Bavaria criticized policies providing the German foreign intelligence agency with competences which, as the leaks of Edward Snowden would later reveal, were then used for the illegal surveillance of German citizens. In the commentary, as in similar contributions to the discourse on security surveillance, the metaphor of the "transparent citizen" stands for the transparency of a citizen's personal traits, preferences, or behavior to the "eye" of a surveilling other - in this case the intelligence agencies.

The metaphor illustrates a specific perspective on the relationship between transparency and surveillance: one in which transparency, understood as the absence of an obstacle in the process of observation, is a precondition for surveillance, as it allows actors "to oversee"-from the French sur [over] + veiller [watch] - others. Surveillance, in turn, entails observation or the gathering of information, not as passive monitoring but for the purpose of "discipline" (Foucault 1995), "behavioral modification" (Zuboff 2015), or "influence, management [or] protection" (Lyon 2007); that is, forms of social control. Thus transparency empowers surveillance and therefore might not be seen as a solely positive but as an ambivalent condition - depending on who it is that is empowered in relation to whom.

The commonplace positive connotation of transparency seems to rely on the equally common assumption that an increase in transparency usually benefits the weaker actors in asymmetric power relations, for example, the citizens in their relations to elected officials. However, it may more often be the case that it is the stronger actors who are able to define the terms of transparency and who can use the possibilities transparency offers.

In order to determine whether an increase in transparency in a specific situation is desirable or not, it is (among other things) important to clarify which actors the increase in transparency might enable to carry out surveillance and which actors might be subjected to that surveillance-although this analytical task has generally not become easier in the past decades. With the rise of new information and communication technologies, the practice of surveillance has disseminated throughout society. An increasing number of actors are involved in acts of surveillance, often simultaneously playing both the role of the surveillant and the role of the surveilled. This is particularly the case in the context of social media. The transparency available in the setting 
of social media platforms is utilized by actors such as the end users, thirdparty developers, advertising clients, government agencies, and the platform providers themselves. Furthermore, these actors often switch between roles in acts of surveillance. End users may, for example surveil other end users while at the same time being themselves surveilled by platform providers.

These diverse actors, however, vary in their degree of agency. As Trottier puts it, "On first pass it seems that all social media users have the potential to watch over each other. But those who manage [the platform] have a privileged view of its contents" (Trottier 2011). Because providers are developing and deploying the software at the heart of platforms and are defining their terms of use, they have more control over the platforms than any other group of actors. It is the providers that first and foremost decide who will be transparent for whom. Therefore, it is the providers and their interaction with other relevant actors that is the focus of this article. The question addressed in the following is why and how providers are furthering transparency and surveillance of the largest and most exposed group of actors, the platform's end users.

As authors like Fuchs $(2012,2014)$ and Zuboff $(2015,2019)$ have shown, answers to this question can be found by analyzing the economic function of surveillance in platform economies. From a Marxist perspective, they have argued that surveillance has become the key component of a new mode of production that constitutes a new variant of the capitalist economic order, which Zuboff $(2015,2019)$ calls "surveillance capitalism." This chapter follows Fuchs and Zuboff insofar as it highlights the economic function of surveillance on platforms. However, it does so not from a Marxist macroeconomic perspective but by relying on concepts of microeconomic literature on platform economics, which help to further the understanding of why and how specific firms (namely, the most successful firms) in specific markets (namely, markets for social media) are deciding to make surveillance an integral part of their business. Particularly useful are the concepts of "network effects" and "multi-sided markets," which have been advanced in the last two decades by works of authors such as Rochet and Tirole (2003), Weyl (2010), and others. In the next section, the concept of network effects will be touched upon in order to explain why concentration in markets for social media occurs and how this affects user privacy. The section thereafter will explain how the multisided market strategy of a social media platform provider may create interest in surveillance. The discussion will be illustrated with examples from Facebook, Inc., which, based on the number of end users, is the provider of the largest social media platform.

\section{Economic underpinnings of surveillance and transparency on social media platforms}

Today, providers of social media platforms belong to the most successful companies in the world. Facebook, Inc., for example, ranks fifth among the most 
valuable corporations (Wikipedia 2020; Handelsblatt 2018). An important reason for the high market capitalization of the platform providers (676 billion US dollars in the case of Facebook) is the degree of concentration in the respective markets. Most of the platforms dominate specific markets, which becomes visible when looking at the number of end users of these platforms, which in some cases is not only high in relative but also in absolute numbers. The platforms run by Facebook are a good example, among which are the platforms Facebook, Instagram and WhatsApp with 2.76 billion daily active users in total (Facebook 2021). For comparison, in the relatively competitive sector of instant messaging the closest competitor to Facebook, Inc.Snap - has around 293 million daily active users on its platform Snapchat (Snap 2021). As interactions are increasingly concentrated on individual platforms, it is not surprising that the monetization of these interactions has led to a strong concentration of capital at the platform providers. However, the market concentration has not only economic or financial consequences but also consequences for the privacy of the platforms' end users.

\section{Concentration in markets for social media and its implications for mass surveillance}

As authors like Helen Nissenbaum (2004) have argued, privacy is highly context-specific as people usually do not object to sharing information per se, but to sharing specific information depending on the social context. They may, for example, want to share personal health information with their physician but oppose sharing the very same information with their neighbors. Thus, in order to safeguard privacy, it is necessary to ensure that information shared is appropriate to and contained within the social context it was meant to be shared. Hypothetically, a decentralized ecosystem of platforms, in which a multitude of platforms exists, would be able to cater to different social contexts - such as specific platforms for communication with family members and other platforms for communication with friends or colleagues, and so on. In a fully centralized ecosystem, in contrast, interactions relating to various social contexts take place on a single individual platform, which has several consequences for user privacy.

One of the consequences of centralization is that end users can be monitored in a wider range of contexts. This is not only a difference in quantity. As has been acknowledged, for example, in court rulings regarding violations of privacy, ${ }^{2}$ the combining of apparently insignificant bits of information can enable the creation of significant data profiles of the persons in question.

A telling example is Facebook's patent on methods that allow the company to use the "staggering" amount of information shared by users-"by sharing photos, real-time status updates, and playing social games" including "information describing recent moves to a new city, graduations, births, engagements, marriages, and the like" (Sullivan et al. 2018) - in order to 
create a profile that provides inferential information regarding other key aspects, such as household income. In short, it is possible to create much more detailed "data doubles" (Ericson and Haggerty 2000) of end users in a centralized ecosystem than in a decentralized one.

Furthermore, the data obtained from users can be distributed more widely in a centralized ecosystem. Users are therefore much more likely to experience what Trottier (2011) with reference to Facebook described as the "leaking" of information from one context to another. They may, for example, share certain information assuming that this information is relevant for their friends, while not realizing that the same information will be disseminated among their family members or colleagues who are present on the same platform. With the very design of the platform, providers like Facebook, Inc. are facilitating the leakage of information, as will be argued below with reference to the examples of the Facebook Beacon and Facebook Timeline.

Finally, in a centralized ecosystem the end users have fewer options to react to unwanted behavior of the platform provider. While they might still be able to voice concerns, their options to exit the relationship to the platform are reduced. Therefore, it is less likely that end users will have leverage to keep the platform provider from introducing problematic practices such as surveillance practices. As authors like Srinivasan (2019) have argued, users on Facebook are unable to react to breaches of their privacy due to Facebook's monopoly status.

To summarize, factors that are conducive for centralization in markets for social media are also conducive for transparency and surveillance of end users on social media platforms. Therefore, it is important to understand the working of such factors. While many different factors may be furthering the concentration of markets, one set of factors that is of particular relevance (and specifically in markets for social media) is economies of scale. Economies of scale may exist both on the supply and the demand side.

On the supply side, economies of scale exist when the average costs of production decrease as outputs increase. Typical examples can often be found in markets for infrastructure. In the case of railways, for example, offering a customer the service in question (transportation by train) incurs almost the same cost in the case of one customer as compared to the case of a thousand customers. There are high fixed costs for the construction of the railway system and relatively low variable costs, such as personnel costs, for its operation. In other words, once the infrastructure is in place, the costs per customer fall rapidly so that a large provider can operate more cost-efficiently than a small provider.

The same logic applies to a different degree to social media. Offering the communication services of a social media platform to a single customer is almost as expensive as offering the same service to a thousand customers. In both cases, the key component of the platform, its software, has to be developed and deployed. Thus, the same high fixed costs apply to both large 
and small numbers of users. These include costs of research and development, which in the case of Facebook, Inc. amounted to over 10 billion dollars in 2018. Additionally, there are relatively low variable costs to bear, such as costs for the operation of the hardware of the platform. ${ }^{3}$

As a result, providers that can rely on a large customer base have a cost advantage and can offer their services at lower prices than providers with a small customer base. Therefore, once a provider has established a large customer base, it is unlikely that a newly entering provider with an initially small customer base can compete. The respective market therefore tends to a monopoly.

While economies of scale on the supply side promote centralization in the context of social media, centralization is further strengthened by economies of scale on the demand side. Varian, Farrell, and Shapiro $(2004,33)$ use the term "demand side economies of scale" interchangeably with the more widespread term "network effects." The terms refer to a situation in which the marginal utility of a product increases with the number of its users. In such a situation, the service in question provides only minimal utility for an individual user, but a larger group of users increases the utility for each user. Good examples are again the classic and the new markets for infrastructure. Writing about the infrastructure for telephony, for example, Theodore Vail, the President of AT\&T, noted in the company's 1908 annual report to shareholders:

A telephone-without a connection at the other end of the line-is not even a toy or a scientific instrument. It is one of the most useless things in the world. Its value depends on the connection with the other telephone-and increases with the number of connections.

(AT\&T 1908)

This is also the case with social media platforms. If the platform were used by only one individual, it would be absolutely useless. If, however, the number of users increases, the utility of the platform for each user also increases.

Fortunately, today's telephone customers can contact any other telephone customer regardless of which specific telecommunications provider they use. This is not the case for social media users. A Facebook customer, for instance, is not able to contact a customer on another platform, such as Diaspora. In this situation, customers have strong incentives to select the provider catering to the larger number of end users. Therefore, once a provider has established a large user base it is likely to dominate the market.

This may even lead to a lock-in situation (Varian, Farrell, and Shapiro 2004, 21). In such a case, even if a majority of users would prefer to switch providers, they are unable to do so collectively and therefore remain. In this case, users are de facto missing one of the fundamental options for reacting to a decrease in service quality, namely the option to exit the relationship with the provider and to select an alternative provider. As Srinivasan (2019) argues, 
Facebook is one example of such a lock-in. Srinivasan considers Facebook's extensive use of user data as a decrease in the quality of Facebook's service, yet end users are unable to react against it by exiting, due to Facebook's monopoly position.

To summarize, economies of scale contribute to the competitive advantages of large platforms and therefore allow providers like Facebook, Inc. to acquire a dominant position in the market for social media. This results in a situation in which the communicative processes of large parts of society are concentrated on individual platforms. In this situation a single platform provider has the ability to oversee a large variety of interactions of users and to expose users to a large variety of settings. Furthermore, it limits the users' ability to react to that oversight and exposure. While therefore the tendency for concentration in markets of social media explains why platform providers acquire a position that is particularly suited for surveillance of end users, it does not explain why the providers are actually interested in using this position. In order to understand the providers' interests, it is necessary to consider their best options for beneficial economic exchanges with their counterparts. Here it is necessary to consider that, in contrast to more traditional companies, platform providers do not have only one key market in which they are active but rather face so-called multisided markets.

\section{A multisided market strategy and its implications for mass surveillance}

By definition platform providers ${ }^{3}$ mediate between different groups of market participants (Evans and Schmalensee 2016). The main function of a platform is to enable interaction among these groups. In order to understand not only how a provider of a specific platform is generating revenue but also whether and how the provider relies on transparency and surveillance to do so, it is necessary to look at how the different groups of actors are being integrated and how externalities among them are managed.

Which groups of actors are integrated into a platform and in what way depends mainly on the strategy chosen by the individual platform provider. According to the definition of social media, end users always take part in the interactions on a platform. However, depending on the particular strategy applied by the provider in question and the resulting design of the platform, additional groups often also take part. In the case of Facebook, for example, there are arguably three main groups of actors, which are the end users, thirdparty developers, and advertising clients. The following will describe the strategies that Facebook applies toward the three main groups of actors on its platform, in order to elaborate the nature of its business model, which seems to have become the dominant model for providers of platforms not only but particularly in social media. 


\section{Strategy toward end users}

It is a constitutive aspect of social media that end users are able not only to consume but also to produce content. Therefore, end users take two different roles on social media platforms: on the one hand, they create a supply of data, and on the other hand, they also create a demand for that data. Platform providers like Facebook, Inc. enable supply and demand to meet. In this constellation the providers (and also the end users) benefit from such network effects. Among the end users, these network effects are bilateral. ${ }^{4}$ The more supply-generating end users the platform has, the more relevant it is for demand-generating end users; and the more demand-generating end users a platform has, the more supply-generating end users it will attract. As argued above, these network effects enable rapid growth of platforms.

For this reason, platform providers try to strengthen the network effects with both their pricing as well as the design of their platform. With their pricing, providers often lower the barriers to entry of end users by setting prices extremely low-often at zero. In this way the providers try to ensure that they succeed in the competition for end users, which — due to the network effectshas a winner-takes-all characteristic. On the other hand, this means that no revenue is provided from the end users directly and that the revenue necessary to sustain the platform has to be derived from other groups of actors. As will be discussed below, in the case of Facebook, these are mainly the advertising clients.

Regarding the platform design, the platform providers have to ensure that it serves the function of matching demand and supply for data as effectively as possible, since only then can network effects reach their maximum intensity. In the case of social media, this may already have implications for the transparency of end users, as it encourages users to seek information about others, even if this imposes costs on those users who experience a breach of their privacy. Indeed, it seems that some platform providers, in their goal to maximize interaction among end users on the platform, have come to the conclusion that a "forced matching" - a matching that lies beyond the supply/ demand of information that would occur if end users had full control-may result in more interaction. Such a forced matching implies either extracting more data from existing end users (in their role as suppliers) than intended by them, or forcing more data on end users (in their role as customers) than actively demanded by them, or both.

Looking at the case of Facebook, Inc. there are several major design decisions that seem to be a result of both strategies. Arguably the most striking examples are the introduction of Facebook's News Feed and Facebook Beacon. Facebook's Newsfeed was introduced in 2006. According to Wikipedia, News Feed is "the primary system through which users are exposed to content posted on the network" (Wikipedia 2019). With the introduction of News Feed, Facebook began to extract the personal information 
of end users from the specific context it was placed in (their profile page) and placed in a much wider context (the News Feed) of - at least potentially - the landing page shown to each of the contacts of the end user. Unsurprisingly, at least when considering Nissenbaum's contextual understanding of privacy mentioned above, many users saw the introduction of the News Feed as a violation of their privacy (Zuckerberg 2006a; Bunz 2006). These users were comfortable with sharing information on their profile page; however, they were uncomfortable with the broadcasting of this information over the landing pages of their contacts. Only after massive protests by users did Facebook introduce options for users to better control the flow of their personal information to the News Feed (Zuckerberg 2006b). However, it did not make the News Feed an optional feature.

Facebook Beacon, introduced in 2007, allowed participating third parties to send information about Facebook users' activities on their websites to Facebook. Online shops, for example, were sending data about the purchases of users to the platform. This data was then placed on the News Feed. In the case of Beacon, users were given little option to control the flow of personal information. The option to opt-out of the service was made available only after user protests, and it prevented only the publishing of the data, not its collection (Zuckerberg 2007). Several protests and a class-action lawsuit were initiated as a response by users. In the course of the lawsuit Beacon was finally terminated (Perez 2009).

As these two examples show, the platform providers' aim of maximizing interaction among users in the case of Facebook already implies a furthering of transparency and surveillance of users. In order to gain a more complete understanding of the providers' interests it is necessary to also consider the providers' strategy toward the other groups of actors integrated into the platform, among them the developers of third-party apps and the advertising clients.

\section{Strategy toward developers}

The developers can be considered as another side in the multisided market that providers like Facebook cater to. In the case of Facebook, developers turn to the platform in order to find consumers for their games and applications. For users, in turn, the games and applications are products to consume. Facebook enables the exchange between the two groups and, by doing so, again benefits from bilateral network effects. The more demand by end users, the more attractive the platform is for developers; conversely, the more applications offered by developers, the more attractive the platform is for users. In this case, too, the company is interested in strengthening the network effects and acts accordingly.

How this goal is followed with a particular strategy for the pricing and design of the platform can be studied particularly well in the case 
of Facebook, since during the Cambridge Analytica scandal that shook the company a large number of documents were published showing how the company developed, exercised, and refined its strategy toward thirdparty developers. Revealing in this context is the correspondence between Facebook's founder and CEO Mark Zuckerberg and other executives of the company, in which the basic principles for the interaction with developers were discussed on the occasion of a new release of Facebook's API (named "Platform"). As becomes clear in this correspondence, it was decided to keep the price for the developers' engagement as low as possible in order to guarantee their presence on the platform. At the same time, ensuring access to data collected by the developers was defined as an overarching principle. This principle has been described with the term "data reciprocity." Mark Zuckerberg explains:

After thinking about platform business model for a long time, I wanted to send out a note explaining where I'm leaning on this. [...] The quick summary is that I think we should go with full reciprocity and access to app friends for no charge. Full reciprocity means that apps are required to give any user who connects to FS a prominent option to share all of their social content within that service [...] back to Facebook.

(Zuckerberg 2012)

He explains further:

[T] he very first question I developed an opinion on was what we should be optimizing for. There's a clear tension between platform ubiquity and charging, so it's important to first fully explore what we're trying to get out of platform. The answer I came to is that we're trying to enable people to share everything they want, and to do it on Facebook. Sometimes the best way to enable people to share something is to have a developer build a special purpose app or network for that type of content and to make that app social by having Facebook plug into it. However, that may be good for the world but it's not good for us unless people also share back to Facebook and that content increases the value of our network. So ultimately, I think the purpose of platform - even the read side - is to increase sharing back into Facebook.

(Zuckerberg 2012)

What becomes clear here is that from the perspective of the provider Facebook, Inc., interaction with developers has a primarily instrumental purpose. The developers are intended to contribute to the transparency and surveillance of end users. In order to ensure this, the provider minimizes barriers to the participation of the developers while obligating them to assist via their apps in the collection of data on the platform. 
How significant the collection of data from third-party developers is becomes particularly clear when considering the case of Cambridge Analytica. In this case, an app (named "thisisyourdigitallife"), developed by a third party, namely Global Science Research, was used to gather the personal information of around 50 million Facebook users. The data was then acquired by the company Cambridge Analytica in order to use it for manipulating end users during several US elections, including the presidential election of 2016. The case was widely perceived as the greatest surveillance scandal in the history of Facebook.

\section{Strategy toward advertising clients}

A third set of relevant actors that needs to be considered in order to understand the platform providers' interest in transparency and surveillance, in this case consists of those individuals and organizations that use the platform for the purpose of advertising. The advertising clients can be understood as resembling another demand side in the multisided market that Facebook decided to cater to. On the opposite side are the end users whose attention is supplied to the advertising clients. The network effects here, however, are unilateral. An increase in the number of users leads to an increase in the value of the platform for advertisers. Conversely, an increase in the number of advertisers does not (or at least only in a very small fraction of cases) lead to an increase in the value of the platform for users. In such a situation, the option preferred by the platform provider is usually not (as in the case of the end users or the developers) to lower the barriers of entry to the platform as far as possible. In contrast, the preferred option is to restrict and price this access. Facebook's annual reports state that in the year 2020 , more than $98 \%$ of the revenue of Facebook was derived neither from end users nor developers but from advertising clients (Facebook 2020). As this number shows, Facebook is following a subsidizing strategy according to which profits are generated on the part of advertising clients to finance the participation on the part of end users and developers. This strategy allows Facebook to strengthen desired network effects regarding end users and developers while at the same time ensuring revenue from the advertising clients, thus ensuring successful competition and ultimately profit maximization.

However, this strategy also comes with obligations regarding the platform's design. The platform must be designed in such a way that it provides a particularly useful service for the only customers directly financing the platformthe advertisers. At this point, it is important to emphasize that the service that advertisers are purchasing is the modification of the end users' behavior, which rests on the surveillance of these end users and their contacts (Zuboff 2019, 68). Most of the demand for this service derives from companies that want to ensure that end users purchase certain products or services that they would not purchase otherwise. The spectrum of decisions affected in these 
cases is far ranging, from a decision about the brand of one's next winter coat, for example, to a decision regarding a future place of residence or the choice of one's next employer. However, the spectrum of affected suser decisions ranges even further since it is not only actors with economic interests that are demanding the service. Religious groups, political movements, political parties, NGOs, and government authorities may also have an interest in influencing a platform's end users. Decisions that can be affected thus also include, for example, the users' religious and political orientation. The advertising systems of Facebook are open to a wide range of clients and mainly leave it to the clients to decide the content used for the advertising.

In any case the effectiveness of the advertising is furthered by relying on the gathering of large amounts of data. First, the data is used to allow clients to select those end users whose behavior they deem particularly easy or particularly useful to manipulate. For a client advertising for yoga courses it may be important to address users who are interested in yoga. For a political party it may be particularly relevant to address users who are "swing voters," or who live in "swing states." Second, the information on end users allows the clients to address the users in particularly effective ways. A user may, for example, be informed that a contact is interested in a yoga course or particular political content. Thus, the users' trust in their contacts and their contacts' decisions is utilized for the advertising. Importantly, the information gathered on end users allows clients to evaluate whether a particular marketing campaign was successful or not. The client may learn which advertising was most successful by considering the percentage of users that reacted to their content by following external links, for example. Thus, the advertising clients may learn and find the optimal approach for running an advertising campaign. As this shows, the effectiveness of advertisement rests to a high degree on the surveillance of end users. Only if the provider, in this case Facebook, has extensive information about the end users can it target those end users whose manipulation is profitable. Only extensive information about these end users allows effective modification of their behavior, and only continuous monitoring allows the advertising clients to learn from their attempts.

To summarize, Facebook's goals of maximizing the participation of end users, third-party developers, and advertising clients leads it to promote the transparency of its end users. What bears mentioning is that this transparency of end users stands in stark contrast to the level of transparency of the platform provider itself. One telling example also in this context is again Facebook's internal communication (Facebook 2013). Among this communication is an email from February 2015 in which Michael LeBeau, then a product manager at Facebook, informed his colleagues about plans to use the Facebook app for gathering data on users' call history - another important step toward increased end user transparency and surveillance. In order to enable the gathering of data, the permissions for the app needed to be changed, which was expected to trigger the Android operating system to start a dialog 
with the users and to inform them about new far-reaching authorizations. Knowing that users would likely object to this step toward more transparency and surveillance of themselves, and knowing that the change would therefore be "a pretty high-risk thing to do from a PR perspective" (LeBeau 2015), Facebook's managers searched for a solution. What they finally proposed was a procedure that "would allow [them] to upgrade users without subjecting them to an Android permissions dialog at all" (Kwon 2015). Thus, as the internal communication shows, the goal of the platform provider here was not to find alternatives to the newly introduced surveillance practice but to simply leave users unaware of it.

As the example shows, the relation between end users and the platform provider Facebook can be described as highly asymmetrical. Facebook has acquired a favorable position in a highly centralized market, and it uses this position to further surveillance and behavioral modification while it also uses the position to shield itself from critical views.

\section{Conclusion: (asymmetric) transparency and surveillance on social media platforms}

In academic as well as in public discourse, transparency is usually described as a positive feature. In the context of surveillance, however, it proves to be of ambivalent character. As has been argued in this chapter, transparency can be considered a precondition of surveillance. Surveillance, in turn, is a problematic practice insofar as it implies power imbalances. Such imbalances become visible in single incidents of surveillance in which a surveillant is always able to exercise control over a surveilled other. Furthermore, imbalances are visible also at the macro level, as the means of surveillance are not evenly distributed in society but rather concentrated with specific actors. As authors like Trottier (2011, 2012), Fuchs $(2012,2014)$, and Zuboff $(2015,2019)$ have pointed out, in the last decades the means for surveillance have become accumulated particularly by specific economic actors, among which social media platforms play a central role.

In order to understand the reasons for the providers' engagement in surveillance, it is necessary to identify the economic factors affecting these corporate actors' interests. Among these, two specific factors are particularly important. Firstly, economies of scale cause the markets for social media to take a centralized form and promote a situation in which individual providers have the possibility to surveil a large number of end users. Secondly, the fact that the providers utilize this possibility is due to the nature of the multisided markets in which the providers operate. Many providers offer communication services for end users, while their revenue is generated by customers paying for influence over these end users. In order to explain the intensified surveillance taking place on social media platforms, it is important to understand the working of these factors. This chapter described some of the key 
factors relevant to explaining transparency and surveillance on social media platforms like Facebook.

In order to gain a more complete picture of the political economy of social media surveillance it is imperative for future research to consider additional aspects of the platform economy. These should include additional factors conducive to platform surveillance, such as mergers and acquisitions among platform providers, which further the centralization of markets and possibilities for platform surveillance. Such research should also include, however, factors that work against platform surveillance (which were not the focus of this chapter), such as the practice of multihoming, which reduces centralization of markets and possibilities for platform surveillance.

\section{Notes}

1 The nontabloid newspaper with the largest circulation in Germany.

2 See, for example, the ruling of the German Supreme Court of December 15, 1983, in which it acknowledged the so-called "right to informational self-determination" as one of the constitutional rights.

3 This chapter differentiates between the platform provider (an organization, usually a corporation as in the case of Facebook, Inc.) and the platform - a technical artifact.

4 In this chapter, the end users are divided conceptually into two groups, and the network effects are therefore categorized as indirect (between groups of actors) and bilateral. If, in contrast, the end users were considered as one homogenous group, the network effects would have to be categorized as direct (among one group of actors).

\section{References}

AT\&T. 1908. "Annual Report of the Directors of American Telephone and Telegraph Company to the Stockholders of the Year Ending December 31, 1908," https:// beatriceco.com/bti/porticus/bell/pdf/1908ATTar_Complete.pdf.

Bunz, Mercedes. 2006. "Facebook Users Protest over News Feed." The Guardian, www.theguardian.com/media/pda/2009/oct/27/new-facebook-newsfeed-protest.

Ericson, Richard V., and Kevin D. Haggerty. 2000. "The Surveillant Assemblage." British Journal of Sociology 51(4): 605-22.

Evans, David S., and Richard Schmalensee. 2016. Matchmakers: The New Economics of Multisided Platforms. Boston: Harvard Business Review Press.

Facebook. 2013. "Industry Update," www.parliament.uk/documents/commonscommittees/culture-media-and-sport/Note-by-Chair-and-selected-documentsordered-from-Six4Three.pdf.

Facebook. 2021. "Facebook Reports First Quarter 2021 Results" https://investor. fb.com/investor-news/press-release-details/2021/Facebook-Reports-First-Quarter2021-Results.

Foucault, Michel. 1995. Discipline and Punish: The Birth of the Prison, 2nd Edition. New York: Vintage. 
Fuchs, Christian. 2012. "Google Capitalism.” TripleC: Communication, Capitalism \& Critique. Open Access Journal for a Global Sustainable Information Society 10(1): 42-8.

Fuchs, Christian. 2014. Social Media: A Critical Introduction. Los Angeles: Sage.

Handelsblatt. 2018. "Apple, Google, Amazon: Das sind die Zehn Wertvollsten Unternehmen der Welt." Handelsblatt, www.handelsblatt.com/finanzen/ anlagestrategie/trends/apple-google-amazon-das-sind-die-zehn-wertvollstenunternehmen-der-welt/22856326.html.

Kwon, Yul. 2015. "Note by Damian Collins MP, Chair of the DCMS Committee." E-mail Message, February 4, 2015, www.parliament.uk/documents/commonscommittees/culture-media-and-sport/Note-by-Chair-and-selected-documentsordered-from-Six4Three.pdf.

LeBeau, Michael. 2015. "Message Summary [id.663395043771422]." E-mail Message, February 4, 2015, www.parliament.uk/documents/commons-committees/culturemedia-and-sport/Note-by-Chair-and-selected-documents-ordered-from-Six4Three. pdf.

Lyon, David. 2007. Surveillance Studies: An Overview. Cambridge; Malden: Polity Press.

Nissenbaum, Helen. 2004. "Privacy as Contextual Integrity." Washington Law Review 79(1): 119-57.

Perez, Juan Carlos. 2009. "Facebook Will Shut Down Beacon to Settle Lawsuit." The New York Times, https://archive.nytimes.com/www.nytimes.com/external/idg/2009/ 09/19/19idg-facebook-will-shut-down-beacon-to-settle-lawsuit-53916.html.

Rochet, Jean-Charles, and Jean Tirole. 2003. "Platform Competition in Two-Sided Markets." Journal of the European Economic Association 1(4): 990-1029.

Snap 2021. "Snap Inc. Announces First Quarter 2021 Financial Results" https://investor. snap.com/news/news-details/2021/Snap-Inc.-Announces-First-Quarter-2021Financial-Results.

Srinivasan, Dina. 2019. "The Antitrust Case Against Facebook: A Monopolist's Journey Towards Pervasive Surveillance in Spite of Consumers' Preference for Privacy." Berkeley Business Law Journal 16(1): 39.

Sullivan, Brendan M., Gopikrishna Karthikeyan, Zuli Liu, Wouter Lode Paul Massa, and Mahima Gupta. 2018. "Socioeconomic Group Classification Based on User Features." United States US20180032883A1, filed July 27, 2016, and issued February 1, 2018, https://patents.google.com/patent/US20180032883A1/en.

Trottier, Daniel. 2011. "A Research Agenda for Social Media Surveillance." Fast Capitalism 8(1): 59-68.

Trottier, Daniel. 2012. Social Media as Surveillance: Rethinking Visibility in a Converging World. Farnham and Burlington: Ashgate.

Varian, Hal R., Joseph Farrell, and Carl Shapiro. 2004. The Economics of Information Technology: An Introduction. Cambridge: Cambridge University Press.

Weyl, E. Glen. 2010. "A Price Theory of Multi-Sided Platforms." American Economic Review 100(4): 1642-72.

Wikipedia. 2019. "News Feed," https://en.wikipedia.org/w/index.php?title=News_ Feed\&oldid $=925280364$.

Wikipedia. 2020. "List of Public Corporations by Market Capitalization," https://en.wikipedia.org/wiki/List_of_public_corporations_by_market_ capitalization\#2020.

Zuboff, Shoshana. 2015. "Big Other: Surveillance Capitalism and the Prospects of an Information Civilization.” Journal of Information Technology 30(1): 75-89. 
Zuboff, Shoshana. 2019. The Age of Surveillance Capitalism: The Fight for a Human Future at the New Frontier of Power. New York: PublicAffairs.

Zuckerberg, Mark. 2006a. "Calm Down. Breathe. We Hear You." The Zuckerberg Files, https://epublications.marquette.edu/zuckerberg_files_transcripts/114.

Zuckerberg, Mark. 2006b. "An Open Letter from Mark Zuckerberg.” The Zuckerberg Files, https://epublications.marquette.edu/zuckerberg_files_transcripts/12.

Zuckerberg, Mark. 2007. "Thoughts on Beacon." The Zuckerberg Files, https:// epublications.marquette.edu/zuckerberg_files_transcripts/14.

Zuckerberg, Mark. 2012. "Platform Model Thoughts." E-mail message, November 19, 2012, www.parliament.uk/documents/commons-committees/culture-media-andsport/Note-by-Chair-and-selected-documents-ordered-from-Six4Three.pdf. 